\title{
ANALYSIS OF WEB-BASED GNSS POST-PROCESSING SERVICES FOR SHORT DURATION STATIC AND KINEMATIC POSITIONING
}

\author{
A. El-Mowafy \\ Department of Spatial Sciences \\ Curtin University of Technology, GPO Box U1987, Perth, WA 6845, Australia \\ a.el-mowafy@curtin.edu.au
}

\begin{abstract}
In this paper the use of some of the currently available web-based online engines for the processing of static and kinematic data from a single dual-frequency receiver is evaluated. The study focuses on using these processing services for the determination of the coordinates of temporary control stations from a few hours of observations in the static mode, and in positioning in the kinematic mode, such as in hydrographic mapping, checking as-built utilities and Geographic Information Systems (GIS) data collection. The different services are briefly presented and compared. The static testing was performed using the AUSPOS and CSRS-PPP services. The results show that precision at mm to cm level can be achieved from the former and within a decimetre from the latter. Kinematic testing using the CSRS-PPP service was performed. Its positioning results were compared with independent differential processing of the same data. The impact of varying the data length on the achieved precision is investigated and the resulting positioning error levels are quantified. In general, the precision varies from a few cm to a few decimetres, and it generally improves with longer observation periods. The CSRS-PPP smoothing performance is also evaluated when breaks of satellite visibility take place and compared with the case of good visibility. Some recommendations are given to surveyors interested in using this type of processing service.
\end{abstract}

KEYWORDS: Precise Point Positioning. Web-Based Processing. GPS.

\section{INTRODUCTION}

In current surveying applications, positioning by GPS is used for two main tasks, namely the establishment of control points in a static mode and the estimation of coordinates of surveyed points in kinematic mode. The processing of data for both positioning modes, static and kinematic, is nowadays possible via free online webbased processing engines. Several organisations have set up web sites where dualfrequency GPS data, uploaded to a centre, can be processed free of charge. These services can process data from all over the globe. This helps in reducing the equipment, personnel and logistics costs compared to conventional GPS surveying, or when establishing reference stations in remote areas. The user needs to work with one receiver only, usually of a geodetic-grade dual-frequency type, collect the data, and transform it into the Receiver Independent EXchange (RINEX) format. Then, the user typically uploads the data to the processing engine via the internet, or in some form, the engine retrieves the data through a ftp site. The engine processes the data and sends the result later to the user, also through the internet. Web-based post-processing services usually use station data and products from the International GNSS Service (IGS), and local or continental networks. All services are dependent on the quality of the data and the length of the data span supplied by the user [14].

To estimate the coordinates in the kinematic mode using a single receiver, the Precise Point Positioning (PPP) method is often used. Some PPP processors are 
available online. The achievable PPP precision is very much a function of the implementation and accuracy of the models used in the PPP software; it is also dependent on the quality and content of the observation files. Online PPP kinematic positioning gives a precision ranging from cm-level to some decimetres [1]. Thus, possible applications for PPP kinematic processing include hydrographic surveying, small scale mapping, rapid positioning, positioning for most Geographic Information Systems (GIS) applications and as-built surveys of utilities such as pipelines and cables.

This paper addresses the current web-based post-processing services that can be utilised for general and rapid surveying applications. The latter include the establishment of temporary control points, which can be computed from only a few hours of collected data, as well as services for kinematic positioning. Testing of these services is conducted. An analysis of the data is presented and some recommendations are given.

\section{ONLINE PROCESSING FOR ESTIMATION OF CONTROL POINTS (STATIC PROCESSING)}

GPS has now become the preferred tool for establishing geodetic control points. It can even extend to regional, national or continental networks [13]. Instead of occupying known stations for referencing newly established stations in a standard approach, users can utilise Continuously Operating Reference Stations (CORS). The coordinates of these stations are well documented and their measurements for the same observation period during the occupation of the newly established stations can be downloaded from the Internet in RINEX format. The user can process all data using commercial software. Some examples of major providers for continuously operating reference stations data are given in Table 1.

Table 1. Examples of providers of RINEX data for continuously operating reference stations

\begin{tabular}{ccc}
\hline Agency & Website as of November 2008 & Reference Stations \\
\hline $\begin{array}{c}\text { National Geodetic Survey } \\
\text { (NGS) - CORS (USA) }\end{array}$ & http://www.ngs.noaa.gov/UFCORS/ & $\begin{array}{c}\text { GPS sites managed by the } \\
\text { National Geodetic Survey. }\end{array}$ \\
\hline Geoscience Australia & http://www.ga.gov.au/bin/data_server/ & $\begin{array}{c}\text { The Australian Regional GPS } \\
\text { Network (ARGN) \& eight } \\
\text { stations within Australia known } \\
\text { as the Australian Fiducial } \\
\text { Network (AFN). }\end{array}$ \\
\hline Natural Resources Canada & http://www.geod.nrcan.gc.ca/products- \\
& produits/gps_e.php & $\begin{array}{c}\text { Canadian Spatial Reference } \\
\text { System and Global IGS stations }\end{array}$ \\
\hline
\end{tabular}

To save the user the steps of downloading reference station measurements, precise orbits and processing of data, several organisations have set up web sites where dualfrequency GPS data from newly established stations can be up-loaded to, where the data can be processed free of charge. The IGS station data and products, e.g. the 
satellite precise orbits and clocks and the earth's orientation parameters, are usually utilised. They are computed from combined data from the analysis centres' individual contributions and includes a collaborative global tracking network of more than 300 continuously operating GNSS stations. Currently, the major organisations that can provide differential processing of static data at the mm-level suitable for establishing control points are:

1. The Australian Surveying and Land Information Group (AUSLIG) of Geoscience Australia, operating the AUSPOS service.

2. Jet Propulsion Laboratory (JPL, NASA, USA), operating the Automatic Precise Positioning Service (APPS), which replaced the well known Automated GIPSY service in August 2009.

3. The Scripps Orbit and Permanent Array Centre (SOPAC) at the University of California, San Diego, operating the Scripps Coordinate Update Tool (SCOUT).

In addition to the above, the Canadian Spatial Reference System (CSRS-PPP) service can be used, albeit with a slightly lower quality as it uses the precise point positioning method, provided that long observation periods of at least two days are used to reach the mm-precision level [5]. Due to the fact that all of these services use IGS products, which utilise data from of globally distributed stations, one would expect that these services can process data from all over the globe. However, areas where IGS stations are not present within a range of a few hundreds of kilometres (e.g. $<300 \mathrm{~km}$ ) may experience a lower positioning precision. Testing is still needed to evaluate this aspect and to detect areas of poor service. In addition to the above 'global' services, several local organisations operating national CORS networks can provide similar services utilising data from their own networks. Almost all commercial software that is typically used to process such networks includes such a utility; its availability to users depends on the strategy of the operating organisation.

Although the AUSPOS system uses the antenna type and height as read from the RINEX file, the user can enter this information and; thus, can over-ride the details given in the RINEX file. This is important as new antennae may not be loaded in the IGS ANTEX file. The AUSPOS processing results will be returned to the user's email address. The SCOUT service of SOPAC requires that the data is observed in dual frequency. The user cannot upload the data to the SCOUT server; instead, the data must be stored on an anonymous ftp server; it is then retrieved by SCOUT for processing. The results are sent to the user's email address. AUSPOS and SCOUT process the user's data with data from the three reference stations that are closest to the user's site. However, in SCOUT, the user can override the automatic selection of the reference stations and choose other stations.

The APPS service of JPL has no web site to interact with the user. The user sends an email mentioning the anonymous ftp where the data to be processed are stored. A reply email is sent to the user containing the ftp server address from which the results file can be downloaded. AUSPOS is seen as more user friendly whereas both SCOUT and APPS of JPL are somewhat cumbersome in their need for the user to have an 
anonymous ftp server, which may not be available (or may be restricted) for some users. Table 2 summarises the service characteristics of the three systems AUSPOS, SCOUT and APPS. 
Table 2. Summary of some examples of free web-based GNSS data processing services for static mode

\begin{tabular}{|c|c|c|c|c|c|}
\hline Agency & $\begin{array}{l}\text { Name of } \\
\text { service }\end{array}$ & $\begin{array}{c}\text { Website as of } \\
\text { November } 2008\end{array}$ & $\begin{array}{l}\text { Type of } \\
\text { service }\end{array}$ & $\begin{array}{l}\text { Used reference } \\
\text { stations and } \\
\text { products }\end{array}$ & $\begin{array}{c}\text { Time of } \\
\text { processing } \\
\text { (receive } \\
\text { data) }\end{array}$ \\
\hline $\begin{array}{l}\text { Geoscience } \\
\text { Australia }\end{array}$ & AUSPOS & $\begin{array}{c}\text { http://www.ga.gov. } \\
\text { au/bin/gps.pl }\end{array}$ & $\begin{array}{c}\text { Online GPS } \\
\text { Processing } \\
\text { Service }\end{array}$ & $\begin{array}{c}\text { IGS stations and } \\
\text { products, and } \\
\text { ARGN stations }\end{array}$ & $\begin{array}{l}\text { Results } \\
\text { within } \\
15 \mathrm{~min} .\end{array}$ \\
\hline $\begin{array}{c}\text { Jet } \\
\text { Propulsion } \\
\text { Laboratory } \\
\end{array}$ & APPS & $\begin{array}{c}\text { http://apps.gdgps.n } \\
\text { et/ }\end{array}$ & $\begin{array}{c}\text { Online GPS } \\
\text { Processing } \\
\text { Service } \\
\end{array}$ & $\begin{array}{l}\text { JPL's and IGS } \\
\text { orbit and clock } \\
\text { products }\end{array}$ & $\begin{array}{l}\text { within } \\
15 \text { min. }\end{array}$ \\
\hline $\begin{array}{l}\text { The Scripps } \\
\text { Orbit and } \\
\text { Permanent } \\
\text { Array Centre } \\
\text { (SOPAC) }\end{array}$ & $\begin{array}{c}\text { Scripps } \\
\text { Coordinate } \\
\text { Update } \\
\text { Tool } \\
\text { (SCOUT) }\end{array}$ & $\begin{array}{c}\text { http://sopac.ucsd.e } \\
\text { du/cgi- } \\
\text { bin/SCOUT.cgi }\end{array}$ & $\begin{array}{c}\text { Online GPS } \\
\text { Processing } \\
\text { Service }\end{array}$ & $\begin{array}{c}\text { Data are } \\
\text { collected from } \\
\text { several } \\
\text { operating- } \\
\text { continuously } \\
\text { GPS arrays } \\
\text { worldwide. }\end{array}$ & $30 \mathrm{~min}$. \\
\hline
\end{tabular}

An earlier investigation of the available online GPS processing engines determined the level of performance, found anomalies and developed some guidelines for use in surveying applications [4]. The study discussed the reference frames and factors affecting the precision. Data were obtained from the Australian Regional Network (ARGN) through Geoscience Australia. Recommendations were given for the use of such services for the establishment of low-medium order reference stations for rapid work, remote sites, ultra-long GPS baseline positioning, connections of GPS positioning with the IGS and ARGN system of coordinates and reference stations. Another study used the CSRS-PPP web-based service for the determination of coordinates of geodetic quality [5]. The results of this study showed that, after at least two days of continuous data collection, the PPP solution agreed on average with a more precise solution obtained from the Bernese software to $3.3 \mathrm{~mm}$ in east, $4.8 \mathrm{~mm}$ in north, and $11.8 \mathrm{~mm}$ in height.

For completeness, the online processing of static data using the AUSPOS and CSRS-PPP engines is briefly addressed in a following section and the results of two tests are given. The focus is on the estimation of point coordinates for temporary stations after a few hours of observations. The paper also shows recent system developments which take into consideration the continuing efforts by the IGS to improve the quality of GPS orbits and clock estimates. They have recently achieved about $2 \mathrm{~cm}$ and $0.1 \mathrm{~ns}$ levels [11]. The speed of the data processing is another issue. For instance, it has been reported that the time taken to process the data and send a report using AUSPOS was 20-25 minutes (depending on number of jobs in the queue) [4]. However, our results show that the time needed in 2009 was generally less than 18 minutes. 
The web-based processing services for the data collected in the static mode, e.g. AUSPOS and SCOUT mainly use the double-differenced phase measurements, which can be formulated as:

$$
\nabla \Delta \phi_{t}=\nabla \Delta r_{(t, t-\tau)}+\nabla \Delta d s_{(t-\tau)}-\nabla \Delta d_{i o n o}+\nabla \Delta d_{t r o p o}+\nabla \Delta \lambda N+\nabla \Delta \varepsilon(\phi)
$$

where $\nabla \Delta$ denotes the double-difference operator at the time of receiving the data $(t), \phi$ is the phase measurement, $(t-\tau)$ is the satellite time, where $\tau$ refers to the travel time from the satellite to the receiver. $r_{(t, t-\tau)}$ is the true geometric range, $d s$ is the orbital prediction error, $d_{\text {iono }}$ and $d_{\text {tropo }}$ are the ionospheric and tropospheric errors, respectively. $\lambda$ is the wavelength, $N$ is the integer phase ambiguity and $\varepsilon$ denotes the measurement noise including multipath and the user antenna phase centre variation.

In the kinematic mode, the goal of online post-processing is to determine positions from a single receiver and eliminate the need for the establishment of temporary reference stations to carry out differential positioning. For this purpose, the precise point positioning (PPP) method can be used. The method is based on the processing of un-differenced observations from a single GPS receiver employing precise orbit and clock corrections [16], [10], [9]. However, some errors that are usually ignored in the traditional differencing approach (see Eq. 1), have to be modelled out [6], [7]. These errors include the relativistic error, Sagnac delay, phase wind up, satellite antennaphase centre offset and variation, the inter-frequency bias and site displacement effects due to Earth, ocean tide and atmospheric loading. With PPP, an absolute positioning precision at the $\mathrm{cm}$ or decimetre precision level can be achieved, depending on user dynamics (static or kinematic) [9].

In solving for the unknown position, both code and carrier-phase measurements are usually used to increase the redundancy and to aid the estimation process since undifferenced measurements are utilised. Since the ionosphere is dispersive and frequency dependent, it is suggested that PPP users employ dual-frequency GPS observations to eliminate the first-order ionospheric error. The general model employed can be given as [12]:

$$
\begin{gathered}
\rho_{(t)}^{I F}=\frac{f_{1}^{2} \rho_{1}-f_{2}^{2} \rho_{2}}{f_{1}^{2}-f_{2}^{2}}=r_{(t, t-\tau)}+d s_{(t-\tau)}+c d T_{(t)}+c d t_{(t-\tau)}+d_{t r o p o}+R+S+I+D+\varepsilon\left(\rho^{I F}\right) \\
\phi_{(t)}^{I F}=\frac{f_{1}^{2} \phi_{1}-f_{2}^{2} \phi_{2}}{f_{1}^{2}-f_{2}^{2}}=r_{(t, t-\tau)}+d s_{(t-\tau)}+c d T_{(t)}+c d t_{(t-\tau)}+d_{t r o p o}+ \\
R+S+P W U+A N T+I+D+\frac{c f_{1} N_{1}-c f_{2} N_{2}}{f_{1}^{2}-f_{2}^{2}}+\varepsilon\left(\phi^{I F}\right)
\end{gathered}
$$

where IF denotes the ionospheric free operator, $\rho_{1}, \rho_{2}, \rho_{(t)}$ and $\phi_{1}, \phi_{2}, \phi_{(t)}$ are the pseudo-range code and the phase measurements of the first, second frequencies, and ionosphere-free combination at time (t), respectively. $f_{1}$ and $f_{2}$ are the frequencies of the carrier waves $\mathrm{L}_{1}$ and $\mathrm{L}_{2}$, respectively. $c$ denotes the speed of light, $d T$ and $d t$ are the receiver and satellite clock errors. $R$ is the relativistic error, $S$ is the Sagnac delay, $P W U$ is the phase wind up, ANT is the satellite antenna-phase centre offset and 
variation, $I$ is the inter-frequency bias and $D$ is the combined site displacement effects due to Earth, ocean tide and atmospheric loading.

Besides the Eqs. 2 and 3, modified models were developed. For instance, a code-phase combination in the form of their average to minimise the impact of noise from the pseudorange measurements was proposed [12]. The total tropospheric zenith delay can be modelled using empirical models and mapping functions (e.g. Saastamoinen) or using Global Mapping functions and numerical models of weather forecasts. A detailed discussion of the PPP method including its parameterisation and required modelling can be found in, [1], [7], [9] and [10].

\section{WEB-BASED ONLINE PROCESSING USING PPP APPROACH}

Some PPP processors are available online for post-processing position estimates over the internet from GPS observation files submitted by the user. A popular one is the service provided by the Geodetic Survey Division (GSD) of Natural Resources Canada (NRCan) known as the Canadian Spatial Reference System (CSRS-PPP). This service was designed to be, as much as possible, a self-serve application. It can be used to process GPS observations made anywhere on or near Earth in static or kinematic modes, at anytime of day. For international users the positions can be presented in the International Terrestrial Reference Frame (ITRF), currently ITRF2005 [3]. For a user working in a different coordinate frame, a conversion between the two frames at the epoch of measurements is needed.

The quality of the GPS orbit and clock estimates has recently improved to about 2 $\mathrm{cm}$ and $0.1 \mathrm{~ns}$ [11] and, consequently, the precision of the PPP. However, the PPP application can only process GPS observations if precise GPS orbits and clocks products are available. The CSRS-PPP uses the best products available at the time the data is submitted, utilising the NRCan hourly precise orbit and clock products at 30second intervals (referred to as "EMU") [9]. The CSRS-PPP service has moved from using the IGS ultra-rapid products, which have a delay of 3 hours, to using the NRCan ultra-rapid products, which have a delay of 1.5 hours, counted from the hour of the last observation in the submitted dataset. If the GPS data is submitted the next day, CSRSPPP will mainly depend on the IGS "rapid" products, if submitted 13 days later, CSRS-PPP will utilise the IGS "final" products.

There is no minimum length for a GPS observation session used in CSRS-PPP. In general, the precision of the PPP computed positions will not reach $\mathrm{cm}$ to decimetre level until the carrier phase ambiguities have converged [8]. For short data sets, positions will be calculated using only the pseudo-range observations. Longer data sets are needed to estimate the ambiguities required when using the carrier phase observations [11]. For L1 users, only code observations are used with ionospheric modelling. For dual-frequency data, both code and phase observations are used in an ionospheric-free combination. The processing also includes cycle-slip filtering, applying satellite and receiver antenna phase centres offsets, a reference frame transformation and applying an ocean loading correction.

\section{TESTING AND ANALYSIS OF RESULTS}

\section{Static Testing at Control Stations}

Online GPS processing for the estimation of the coordinates of control stations was evaluated at stations of known coordinates in three countries (located in three 
continents). The tests were carried out in Australia, United Arab Emirates (Asia), and the Netherlands (Europe). The focus here is on establishing temporary control points of a low order, which may be suitable for engineering work requiring a cm-decimetre level of precision. Other studies have addressed the use of web-based processing for the estimation of coordinates of higher order control stations, but that was achieved after collecting observations from long periods (e.g. [2], [14]). In practice, the estimation of coordinates of temporary control points is mostly performed using short data sets (only a few hours of measurements) for logistic and economic reasons. In the first test, pillar number 18 was used, which is located in the Edinburgh Oval Park at Curtin University of Technology, Perth, Australia. A Sokkia GSR2700ISX dualfrequency receiver was used, collecting data for 3 hours and 11 minutes at 10 seconds intervals on 19 November 2008. The data set was later processed twice, using the AUSPOS and CSRS-PPP online web-based services. As stated above, the two techniques are different in methodology. AUSPOS applies a differential approach while CSRS-PPP uses the undifferenced PPP technique. AUSPOS also reference the data to IGS stations, which have a sampling rate of 30 seconds, whereas CSRS-PPP processes the data with its original sampling rate.

In the processing by AUSPOS, the station coordinates were computed from the IGS reference stations, pert, nnor, and yar2, which are located approximately $22.6 \mathrm{~km}$, $109.9 \mathrm{~km}$, and $332.2 \mathrm{~km}$, respectively, from the computed station. Due to the type of processing involved in the AUSPOS (differential with respect to 3 highly accurate IGS reference stations, pert station is only $22.6 \mathrm{~km}$ away, and utilisation of final orbits and clock corrections) it is expected that much better results can be obtained from AUSPOS compared with CSRS-PPP (as PPP is computed based on float ambiguities). It is worth mentioning that the CSRS-PPP results are computed for an epoch corresponding to the mid-point of the submitted GPS observation session for static processing and the exact epochs of the observations for kinematic processing [11].

When comparing the final coordinates from AUSPOS with the known coordinates of the station, the differences were $0.81 \mathrm{~cm}, 0.84 \mathrm{~cm}$ and $1.2 \mathrm{~cm}$ along the East, North and height directions, respectively. The differences of the final computed Cartesian coordinates between processing using AUSPOS and CSRS-PPP are given in the second row in Table 3. However, when mapping the coordinate differences along the East, North, and Height directions, the differences were $0.72 \mathrm{~cm},-1.48 \mathrm{~cm}$. and 8.94 $\mathrm{cm}$ in Universal Transverse Mercator Projection (UTM) as shown in Table 3. These results show clearly that the CSRS-PPP can give very good results for the planimetric coordinates even for a relatively short period of observation (approx. $3 \mathrm{~h}$ ). However, the height error was almost a decimetre (approx. $9 \mathrm{~cm}$ ), resulting in differences in the range of 3-6 cm when mapped in the $\mathrm{X}, \mathrm{Y}, \mathrm{Z}$ directions. The precision (represented by the standard deviations) from AUSPOS and CSRS-PPP processing as given in their reports are listed in the third and fourth rows of Table 3, respectively.

Figure 1 illustrates the carrier-phase residuals of the observed satellites during the observation period and shows that the observations were free from significant cycle slips. Figures 2, 3 and 4 show the latitude, longitude and height changes from the PPP 
solution as obtained from the CSRS processing report. The figures show that the states in the Kalman filter needed at least one hour to stabilise. This indicates that, to obtain a positioning precision for control points at the $\mathrm{cm}$ to sub-decimetre precision level using the CSRS-PPP service, a minimum of one hour of observations is required.

Table 3. Statistics from the AUSPOS and PPP solutions for of the control point

\begin{tabular}{lccc}
\hline & $\mathbf{X}(\mathbf{c m})$ & $\mathbf{Y}(\mathbf{c m})$ & $\mathbf{Z}(\mathbf{c m})$ \\
\hline AUSPOS - CSRS_PPP differences & 3.57 & 5.82 & 5.96 \\
\hline Precision $( \pm 1 \sigma)$ AUSPOS & 1.00 & 1.00 & 0.72 \\
\hline Precision $( \pm 1 \sigma)$ CSRS_PPP & 1.21 & 2.33 & 3.42 \\
\hline & $\mathbf{E}(\mathbf{c m})$ & $\mathbf{N}(\mathbf{c m})$ & $\mathbf{h}(\mathbf{c m})$ \\
\hline AUSPOS - CSRS_PPP differences & 0.72 & -1.48 & 8.94 \\
\hline
\end{tabular}

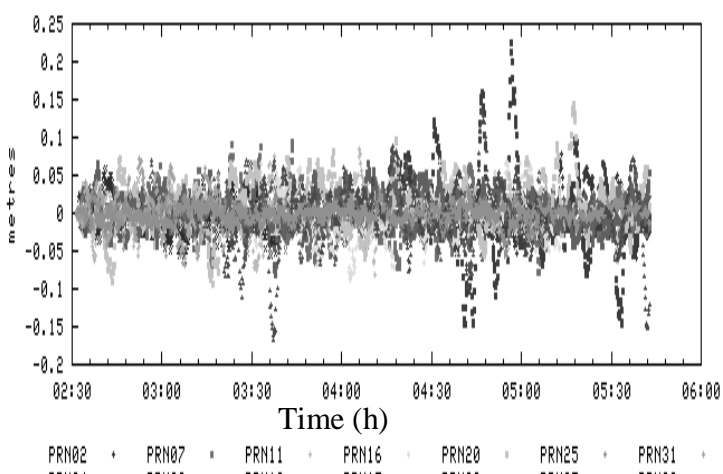

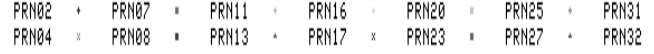

Fig. 1. PPP Carrier-phase residuals (CSRS report)

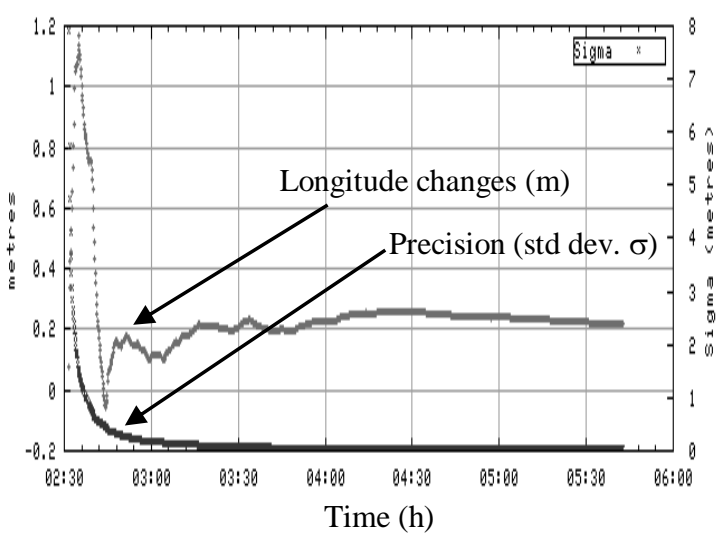

Fig. 3. PPP Longitude changes (CSRS report)

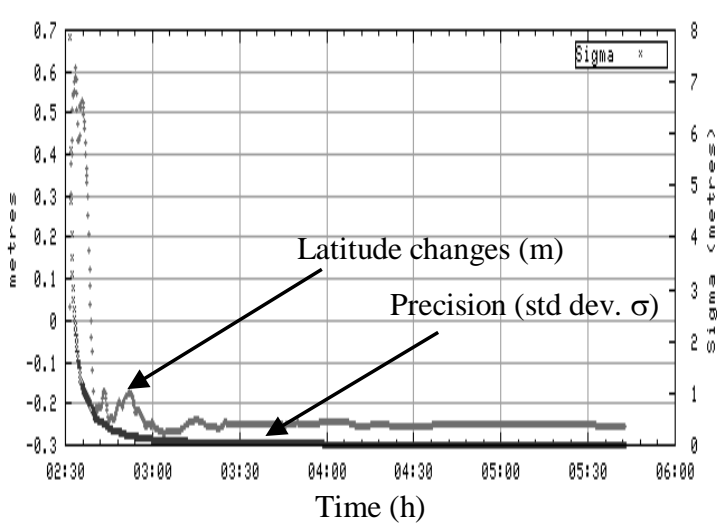

Fig. 2. PPP Latitude changes (CSRS report)

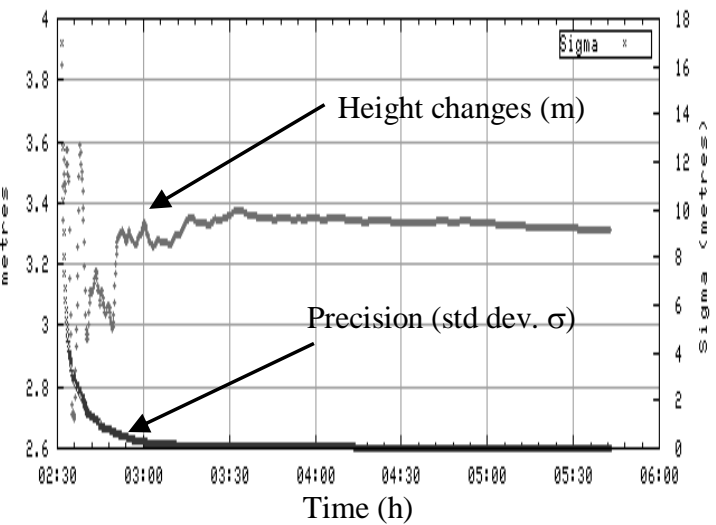

Fig. 4. PPP Height changes (CSRS report)

In the second static test, three hours of data were collected at the station 'dlma' in Abu Dhabi, United Arab Emirates using Leica GPS1200 receiver with 5 seconds sampling rate. AUSPOS processed the data using only one IGS reference station (bhr1), which was the only available IGS reference station within a reasonable distance (approximately $257.7 \mathrm{~km}$ ). The coordinate differences for the station dlma between the CSRS-PPP and AUSPOS solutions were $0.61 \mathrm{~cm}, 0.60 \mathrm{~cm}$, and $1.11 \mathrm{~cm}$, for the UTM East, North and ellipsoidal height components, respectively. 
The data of the third static test were collected in the Netherlands for 2:45 h with one second sampling rate using Trimble R7 receiver. AUSPOS processed the data using three close IGS reference stations: brus, kosg, and redu. The coordinate differences for the test station between the CSRS-PPP and AUSPOS solutions were $1.37 \mathrm{~cm}, 0.92 \mathrm{~cm}$, and $7.20 \mathrm{~cm}$, for the UTM East, North and ellipsoidal height, respectively. Results from the three static tests show that the differences using the two web services CSRSPPP and AUSPOS solutions are typically within the $\mathrm{cm}$ to a decimetre level.

\section{Kinematic Testing}

To evaluate the performance of the web-based post-mission processing of kinematic data, a test was performed on 19 November 2008, in the Edinburgh Oval Park at Curtin University of Technology, Perth, Australia. The test was carried out for almost 3 continuous hours in a walking mode. A Sokkia GSR2700ISX dual-frequency receiver was used for the data collection. The collected data were processed using only the CSRS-PPP online service. To establish a reference for the assessment of the PPP results, another receiver simultaneously occupied a known station (Pillar 18), located in the same area. The data from the reference station were analysed in the static mode as discussed in the previous section. The data of both receivers were later processed in a differential mode, here referred to as post-processing kinematic (PPK) mode. The positions determined by differential processing were compared with the CSRS-PPP positions. The distance between the reference station and the kinematic run was limited to hundreds of metres, which resulted in the elimination of most distance-dependent errors (orbital and atmospheric errors). The mean values of the standard deviations after processing the kinematic data using the PPK approach were $0.54 \mathrm{~cm}, 0.53 \mathrm{~cm}$ and $1.29 \mathrm{~cm}$ for the East, North and height components, respectively. The epoch-by-epoch standard deviations are shown in Figure 5. Since the post-mission differential solution in this case gave a precision at the $\mathrm{mm}-\mathrm{cm}$ level, the differential processing results could be used as the reference "truth" for comparing the CSRS-PPP solution. The spike seen between the epochs 2530 and 2680 was due to passing under a tree canopy, where the number of observed satellites dropped to less than 4.

To evaluate the effect of the length of a data span on the results of the PPP method, four data sets were extracted from the original $3 \mathrm{~h}$ block with different periods but starting from the same epoch. The four data sets were $1 \mathrm{~h}, 1.5 \mathrm{~h}, 2 \mathrm{~h}$, and $3 \mathrm{~h}$ of length. The $1 \mathrm{~h}$ data set is the first hour of the $3 \mathrm{~h}$ data set, the $1.5 \mathrm{~h}$ data set is the first hour and a half of the $3 \mathrm{~h}$ data, and the $2 \mathrm{~h}$ data set is the first 2 hours of the $3 \mathrm{~h}$ data set.
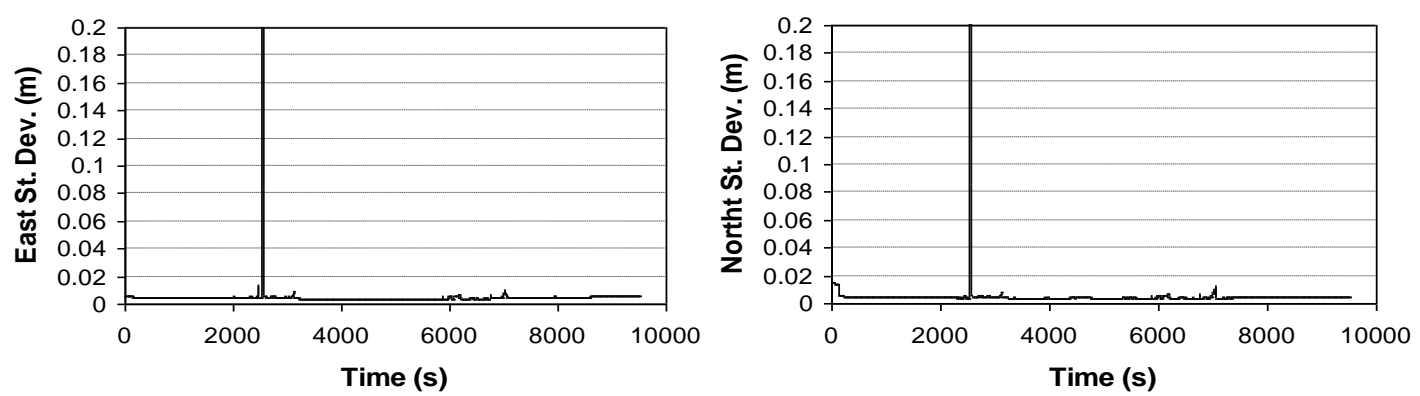


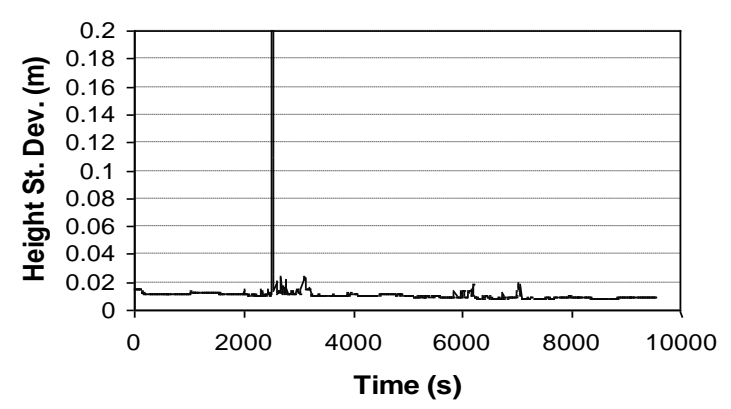

Fig. 5. St. dev. of epoch-by-epoch differential positioning

The statistics of the differences between the PPK and the web-based PPP processing for the four time segments are given in Table 4 in terms of the maximum and minimum values, as well as the overall average after excluding the outliers. The maximum and minimum give the boundaries of the differences, noting that the absolute value of a large minimum may represent the maximum difference between the two solutions. The averages have relatively small values due to the presence of positive and negative differences, which sometimes cancel each other. The statistics are given excluding the outliers, which were defined as the errors that exceed $3 \sigma$ (where $\sigma$ is the standard deviation). There were 183 epochs with outliers that usually coincided with the receiver being close to or under a tree canopy.

Table 4. Differences between PPP and PPK processing for different observation periods

\begin{tabular}{cccccccccc}
\hline & \multicolumn{3}{c}{$\mathrm{E}(\mathrm{m})$} & \multicolumn{3}{c}{$\mathrm{N}(\mathrm{m})$} & \multicolumn{3}{c}{$\mathrm{h}(\mathrm{m})$} \\
\cline { 2 - 9 } & $\max$ & $\min$ & average & $\max$ & $\min$ & average & $\max$ & $\min$ & average \\
\hline $3 \mathrm{~h}$ & 0.171 & -0.254 & 0.001 & 0.204 & -0.282 & -0.052 & 0.527 & -0.452 & -0.153 \\
\hline $2 \mathrm{~h}$ & 0.058 & -0.302 & -0.096 & 0.192 & -0.312 & -0.081 & 0.481 & -0.483 & -0.222 \\
\hline $1.5 \mathrm{~h}$ & -0.031 & -0.368 & -0.149 & -0.305 & 0.188 & -0.207 & 0.430 & -0.048 & -0.125 \\
\hline $1 \mathrm{~h}$ & -0.078 & -0.426 & -0.353 & 0.173 & -0.162 & -0.028 & 0.388 & -0.341 & -0.168 \\
\hline
\end{tabular}

The values given in the Table 4, while shedding some light on the statistics of the expected PPP precision, are still not very representative. For a better analysis of the differences between PPP and post-mission processing (here considered as PPP errors, allowing for 1-2 cm errors in the PPK solution), both the error versus time behaviour as well as the frequency at different error levels were investigated. The change of the error with time can be seen from the time-series plots. Figures 6, 7, 8 and 9 show these plots of the PPP errors for the $3 \mathrm{~h}, 2 \mathrm{~h}, 1.5 \mathrm{~h}$, and $1 \mathrm{~h}$ data spans. The frequencies of errors at different levels is shown by a histogram of the percentage of errors which lie in each error level (category) and are presented in segments of $10 \mathrm{~cm}$, varying from $40 \mathrm{~cm}$ to $+40 \mathrm{~cm}$. These histograms for the $3 \mathrm{~h}, 2 \mathrm{~h}, 1.5 \mathrm{~h}$, and $1 \mathrm{~h}$ data segments are shown in the Figures 10,11, 12, and 13, respectively.

As can be seen from the Figures 6 to 9, the precision generally improves with longer observation periods. This can be seen when comparing the $3 \mathrm{~h}$ time series data set, 
with that of the $1 \mathrm{~h}$ data set (as the two extremes of the testing scenarios), where for the same testing period, errors from the longer data set ranged between $\pm 20 \mathrm{~cm}$, while they were $\pm 40 \mathrm{~cm}$ for the shorter data set. Between these values, errors vary for the $2 \mathrm{~h}$ test and $1.5 \mathrm{~h}$ test. The differences can be attributed to solving the carrier phase ambiguities as float variables (real numbers), in addition to unmodelled errors. Solving for float ambiguities usually requires a long time until the estimated ambiguities, as state vectors in the Kalman filter, reach a steady state. Thus, it is recommended, when running a survey of short time span, to keep the GPS receiver running for a longer time, even in static mode before or after the survey, so that a sufficient length of data is collected.
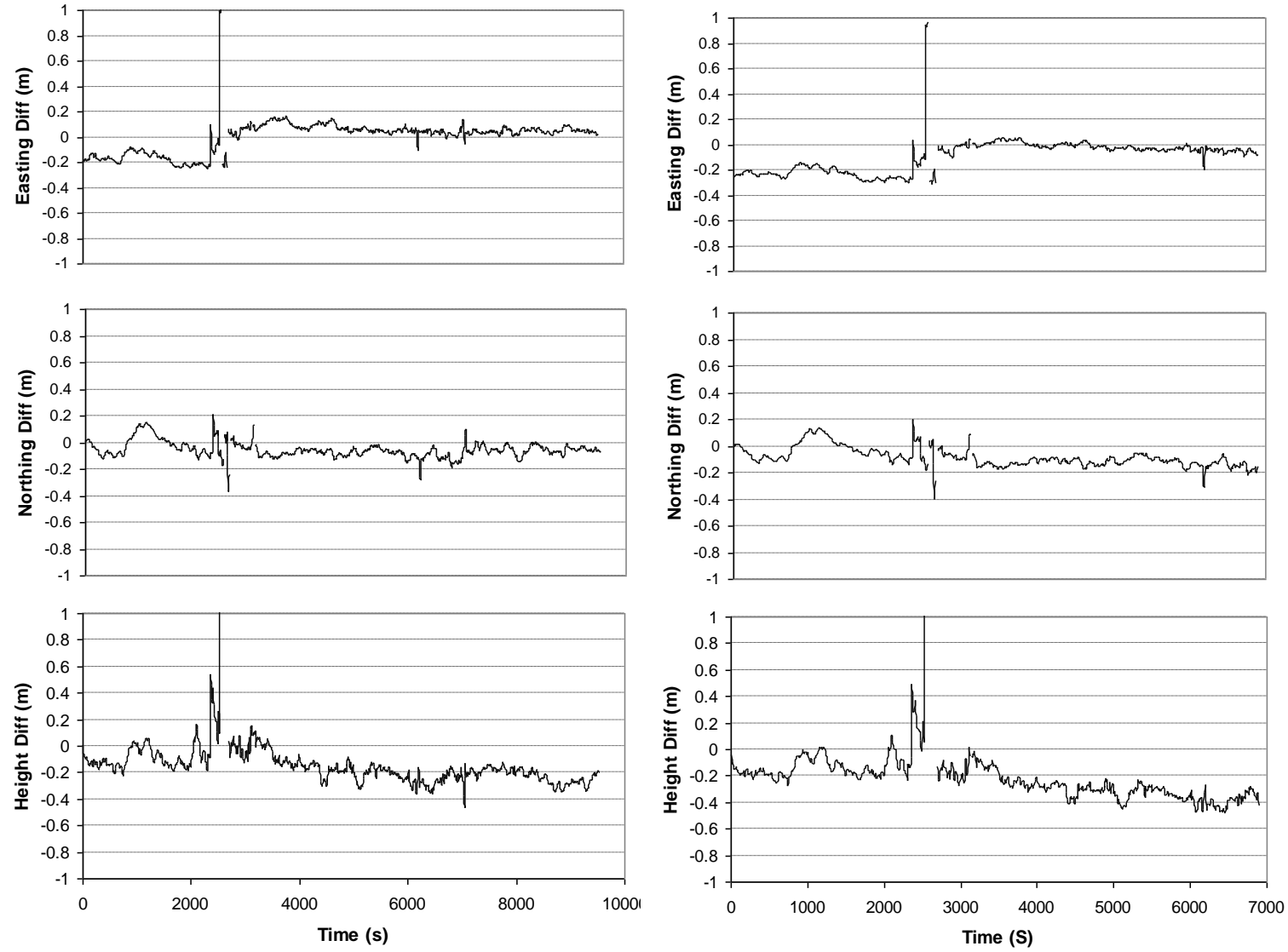

Fig. 6. PPP-PPK differences (3 h data)

Fig. 7. PPP-PPK differences ( $2 \mathrm{~h}$ data)
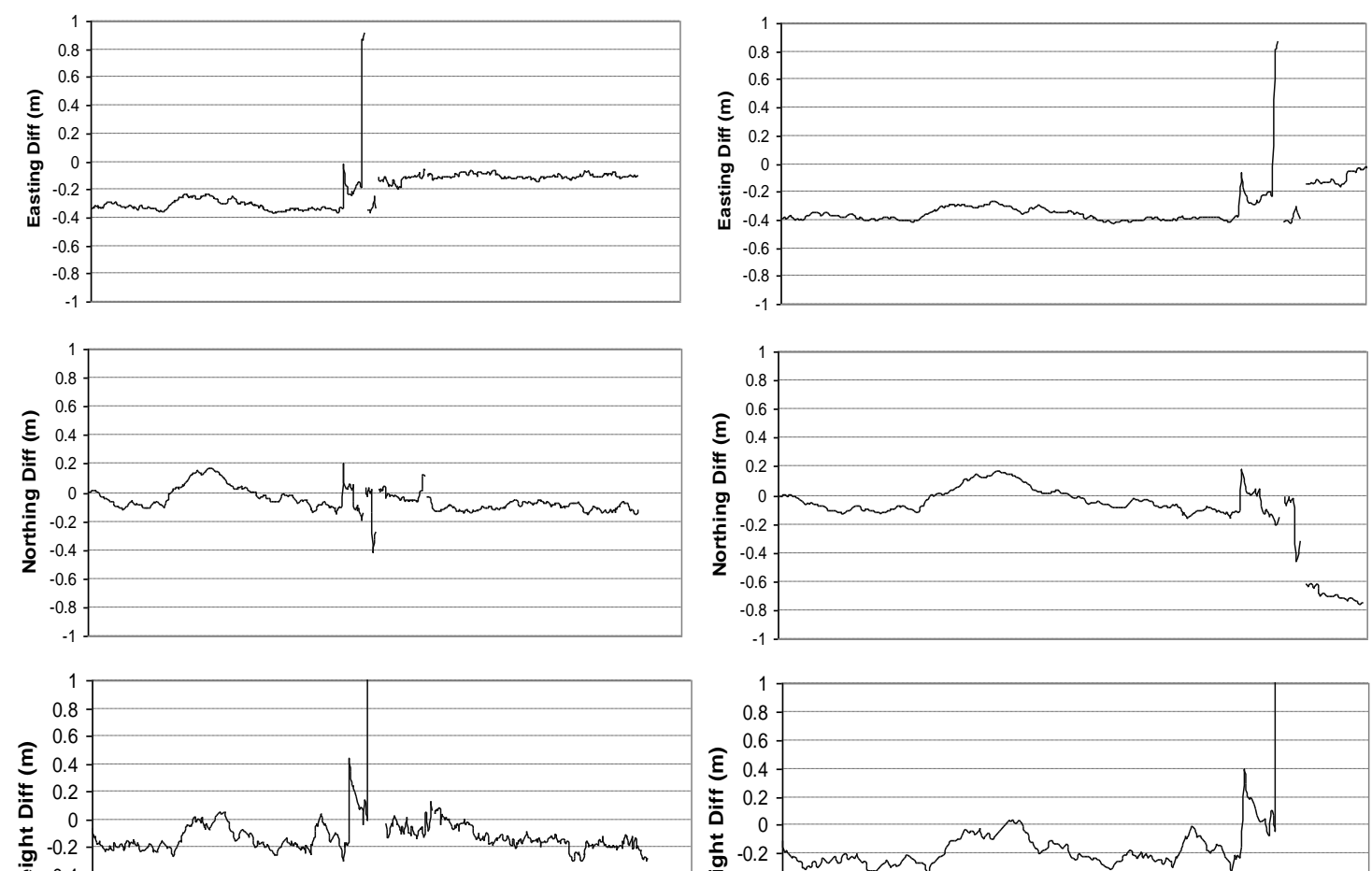
Fig. 8. PPP-PPK differences ( $1.5 \mathrm{~h}$ data)
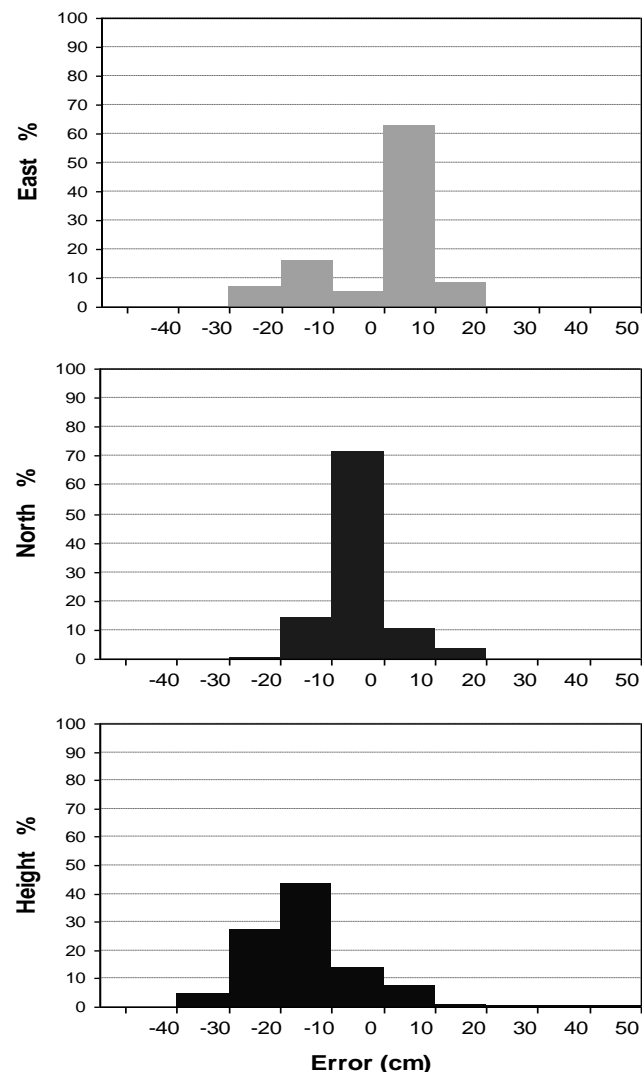

Fig. 10. PPP percentage of error levels ( $3 \mathrm{~h}$ data)
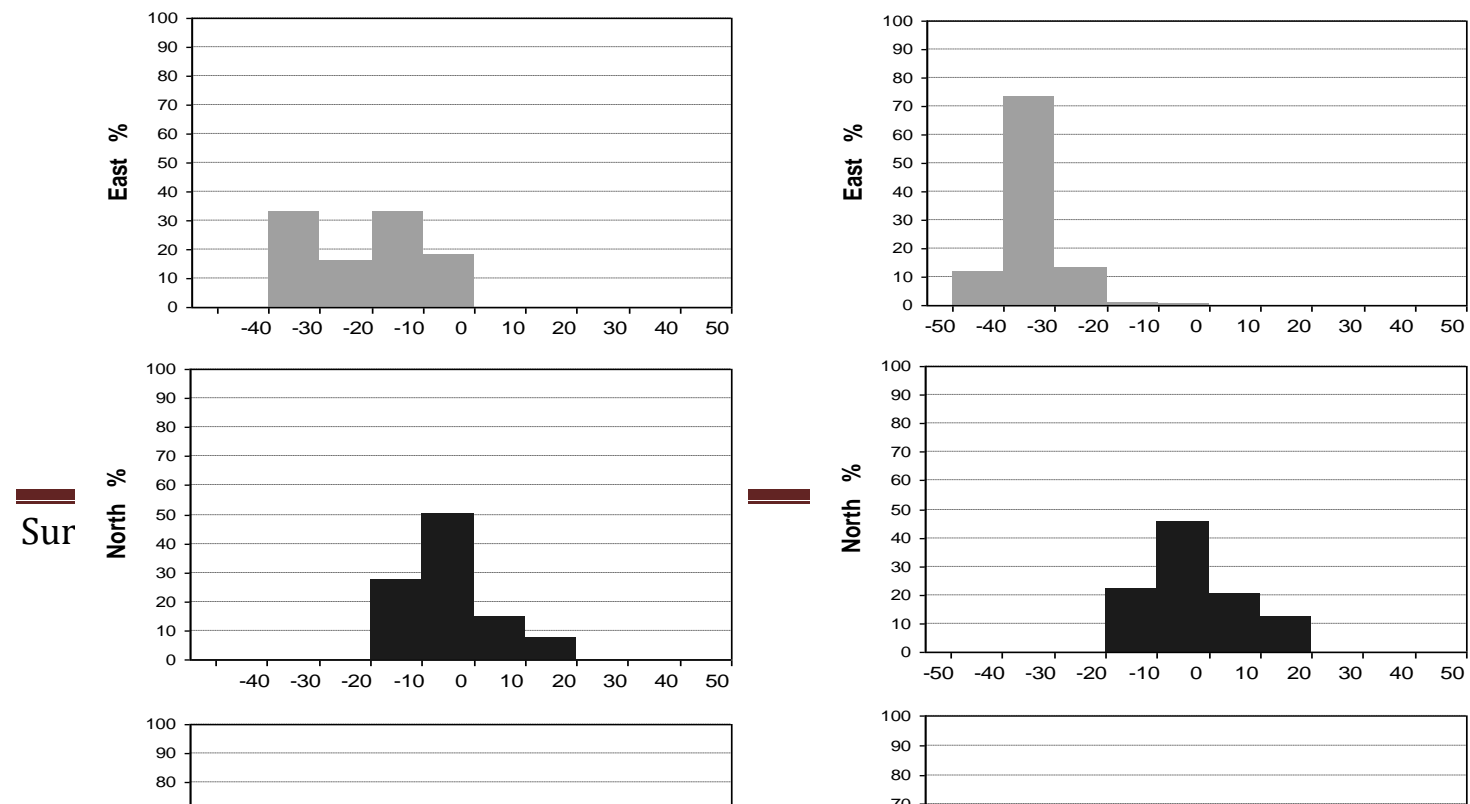

Fig. 9. PPP-PPK differences ( $1 \mathrm{~h}$ data)
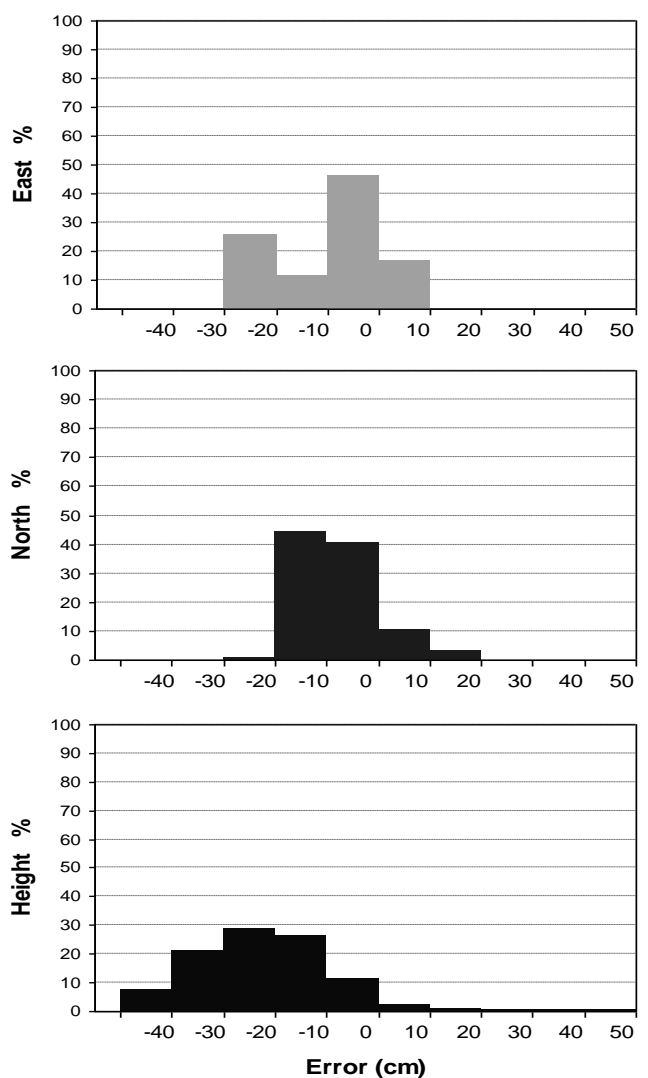

Fig. 11. PPP percentage of error levels ( $2 \mathrm{~h}$ data)
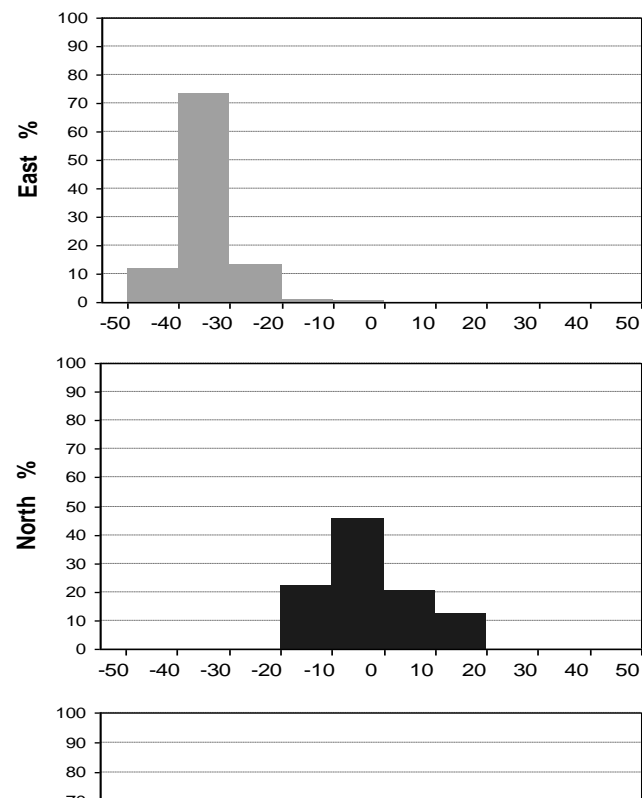
In positioning by GPS, the precision of the North coordinate component $(\mathrm{N})$ can be somewhat worse than the precision of the East coordinate component $(\mathrm{E})$ due to the receiver-satellites geometry at the location of the GPS receiver. Due to the inclination angle of the GPS orbital planes with respect to the equator, which is 55 degrees, the satellites along the East-West direction have a better distribution compared with their distribution along the North-South direction. Thus, the North direction for mid-latitude users may experience a gap in between the GPS satellite orbits. For the test at hand, the differences in precision in the East-West direction compared with those in the NorthSouth direction were not very pronounced. The latter generally performs better in agreement with the findings from other studies, e.g. [15], but not at the same level as in [5]. The results from the latter study show a significant difference between the precision of the North and East coordinate components, but that was for a long observing period in the static mode. The height estimation was frequently worse than the East and North components, which was as expected.

The interpretation of the error percentages shown in the Figs. 10 to 13 confirms the above conclusions. While the majority of errors for the $3 \mathrm{~h}$ data have values between 0 and $\pm 10 \mathrm{~cm}$ for all three components (East, North, Height), the majority of the errors for the $1 \mathrm{~h}$ data set were between -30 and $-40 \mathrm{~cm}$ in the Easting, better than that for Northing $(-20 \mathrm{~cm}$ to $+20 \mathrm{~cm})$, and from $-20 \mathrm{~cm}$ to $-30 \mathrm{~cm}$ for the height. The errors for the $2 \mathrm{~h}$ and $1.5 \mathrm{~h}$ data have patterns that are in-between these two cases.

As mentioned above, the test included a period at the end of the first hour, where the rover went under a tree canopy and satellite visibility was poor. This resulted in a loss of $3 \mathrm{D}$ positioning for a period of 150 epochs. It was interesting to evaluate the impact of this data gap on the results of the remaining period of the $3 \mathrm{~h}$ data set. Thus, a comparison was made between two cases. First, the data of the first hour containing the gap was excluded from the test and the last $2 \mathrm{~h}$ of the original $3 \mathrm{~h}$ data were reprocessed. These data (last $2 \mathrm{~h}$ ) have generally a clear satellite visibility, where the number of observed satellites was above five. Point coordinates produced from this run (of the last $2 \mathrm{~h}$ data) were then compared with the coordinates of the same points as computed from the original $3 \mathrm{~h}$ data set that included the period of interrupted satellite visibility. For this $2 \mathrm{~h}$ period, the differences between the two cases are depicted in 
Figure 14. Their statistics are given in Table 5, first for the differences between the two PPP solutions, and next those from the PPK solution. As can be seen, the differences in the East and North directions were small, with a maximum value of $3.8 \mathrm{~cm}$ and a few millimetres on average. The height showed significant discrepancies, with differences up to $24 \mathrm{~cm}$, but usually within $\pm 10 \mathrm{~cm}$. This proves that the continuity of high quality data will affect the performance of PPP processing.

Table 5. Differences with variable satellite visibility (last $2 \mathrm{~h}$ data)

\begin{tabular}{cccccccccc}
\hline $\begin{array}{c}\text { Diff. of last } \\
\text { 2h of PPP } \\
\text { with }\end{array}$ & \multicolumn{3}{c}{$\mathrm{E}(\mathrm{m})$} & \multicolumn{3}{c}{$\mathrm{N}(\mathrm{m})$} & & \multicolumn{3}{c}{$\mathrm{h}(\mathrm{m})$} \\
\cline { 2 - 10 } & & $\min$ & average & $\max$ & $\min$ & average & $\max$ & $\min$ & average \\
\hline $\begin{array}{c}\text { original 3h } \\
\text { PPP }\end{array}$ & 0.038 & -0.001 & 0.018 & 0.030 & -0.008 & 0.001 & 0.109 & -0.243 & -0.027 \\
\hline PPK & 0.190 & -0.080 & 0.080 & 0.107 & -0.279 & -0.071 & 0.049 & -0.447 & -0.231 \\
\hline
\end{tabular}
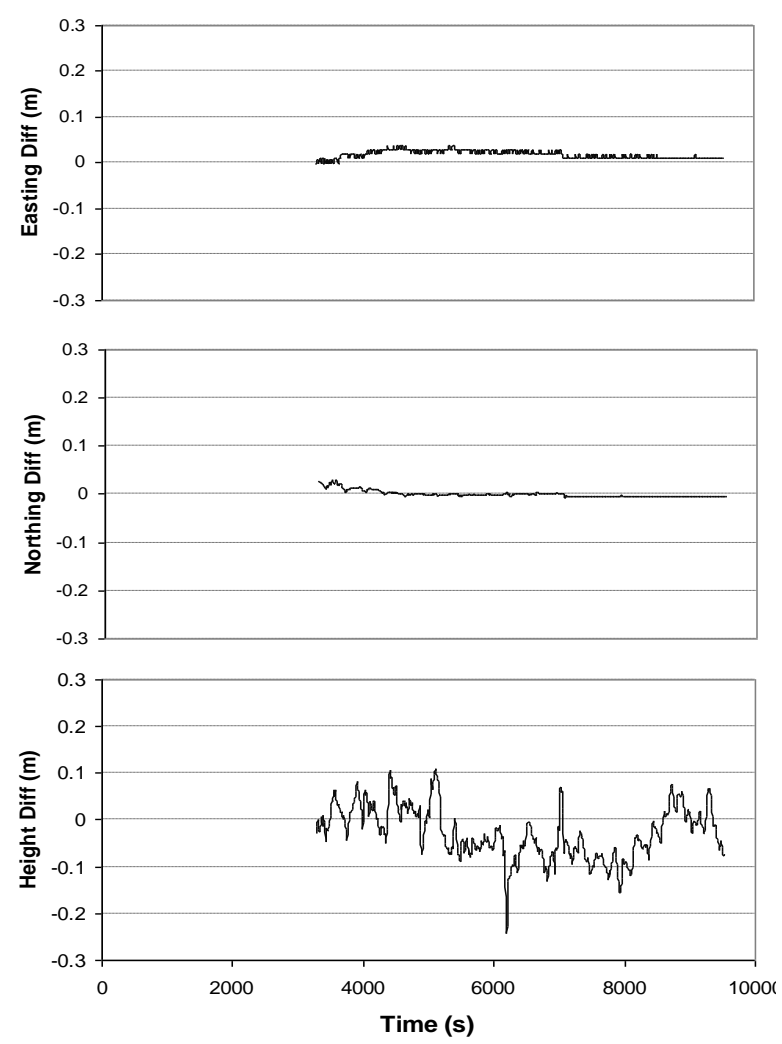

Fig. 14. PPP differences between two scenarios

A second test with a similar approach was performed independently on a different day to verify the above conclusions. In this test, the surveying work was performed in the same test area as the first test. The results from the CSRS-PPP were compared with the post-processed differential measurements. The post-processed differential positions were used as a reference for checking the PPP results. The test duration was approximately 40 minutes. The statistical results of this test are given in Table 6. As can be seen, the differences were almost at the same level of that of the $1 \mathrm{~h}$ data of the first test, which confirms the conclusions drawn above, e.g. the expected positioning 
differences will be at the $\mathrm{cm}$ to couple of decimetres (up to $40 \mathrm{~cm}$ ) for the East and North components and up to $50 \mathrm{~cm}$ for the height component. This shows the expected performance of the PPP in the kinematic mode when processing short periods of data.

Table 6. Differences between PPP and PPK for the a second (40 min) test

\begin{tabular}{ccccccccc}
\hline & $\mathrm{E}(\mathrm{m})$ & & \multicolumn{3}{c}{$\mathrm{N}(\mathrm{m})$} & \multicolumn{2}{c}{$\mathrm{h}(\mathrm{m})$} \\
\hline $\max$ & $\min$ & average & $\max$ & $\min$ & average & $\max$ & $\min$ & average \\
\hline 0.432 & 0.031 & 0.204 & 0.299 & -0.379 & -0.179 & 0.472 & -0.359 & 0.077 \\
\hline
\end{tabular}

\section{CONCLUSIONS AND SUMMARY}

The processing of the data for static and kinematic positioning modes using a single receiver is nowadays possible via free online web-based processing engines. When establishing temporary control points of low order from only a few hours of measurements, the final coordinates from AUSPOS have a precision of a few millimetres to a couple of centimetres. The CSRS-PPP processing service can give very good results at a few millimetres-centimetres for the planimetric coordinates in the static mode. However, height errors can reach a decimetre. The online processing services are available for global use, and the presented results were obtained from three test sites in three continents. However, testing is still needed to evaluate the performance in other areas and to detect those of poor service.

Some PPP processors are available online to estimate the coordinates in the kinematic mode. The CSRS-PPP processing service for kinematic data can give positioning at $\mathrm{cm}$ to some decimetres level, depending on the quality of the data and its length. Its precision generally improves with longer observation periods. In the case of running a survey of a short time span, it is recommended to keep the GPS receiver running for a longer time such that a sufficient amount of data is collected. The continuity of high quality data affects the performance of PPP processing. However, the CSRS-PPP smoothing of data is generally good when using data that include periods of poor satellite visibility. The differences of data with continuous good visibility amount to a few millimetres to some centimetres.

\section{ACKNOWLEDGMENT}

The Mathematical Geodesy \& Positioning group, the Delft Institute of Earth Observation and Space Systems, Delft University of Technology, Netherlands, is acknowledged for providing the data of the Netherlands' static test.

\section{References}

1. Abdel-Salam, M., 2005. Precise Point Positioning Using Un-Differenced Code and Carrier Phase Observations. UCGE Report No. 20229, Dept. of Geomatics Engineering, The University of Calgary, Canada, 206 pp.

2. Altamimi, Z. Sillard, P. and Boucher, C., 2002. ITRF2000: A new Release of the ITRF for Earth Science Applications. J. for Geophysical Research, 107(B10): 1-19.

3. Altamimi, Z., Collilieux, X., Legrand, J. and Garayt, B., 2007. ITRF2005: A new release of the International Terrestrial Reference Frame based on time series of station positions and Earth Orientation Parameters. J. Geophysical Research, B-Solid Earth, 112(B9): B09401.

4. Chu, L., 2002. A Study of Web-Based GPS Processing Engines. M.Sc. Thesis, University of NSW. 
5. Ebner, R. and Featherstone, W. E., 2008. How Well Can Online GPS PPP Post-Processing Services be Used to Establish Geodetic Survey Control Networks. J. of Applied Geodesy, 2(3): 149-157.

6. El-Mowafy, A., 2007. Precise Point Positioning for Mobile Mapping. Proc. of the $5^{\text {th }}$ International Symposium on Mobile Mapping Technology MMT'07, May 28-31, Padua, Italy.

7. El-Mowafy, A., 2009. An Alternative Post-Processing Positioning Approach Based on Precise Point Positioning with Corrections from a Reference Station. J. of Surveying Engineering, 135(2): 56-65.

8. Ge, M., Gendt, G., Rothacher, M., Shi, C., Geng, J., and Liu, J., 2008. Resolution of GPS carrierphase ambiguities in PPP with daily observations. J. Geodesy, 82(7): 389-399.

9. Gao, Y. 2006. Precise Point Positioning and Its Challenges, Aided-GNSS and Signal Tracking. Inside GNSS, 1(8): 16-18.

10. Kouba, J., and Héroux, P., 2001. Precise Point Positioning Using IGS orbit and Clock Products. GPS Solutions, 5(2): 12-28.

11. Lahaye, F., Mireault, Y., Héroux, P., Tétreault, P. and Kouba, J., 2008. A New, Timely Service from Natural Resources Canada. GPS World, Sept. 2008, accessed in Nov. 2008 online: http://sidt.gpsworld.com/gpssidt/article/articleDetail.jsp?id=549570

12. Shen, X. 2002. Improving Ambiguity convergence in Carrier Phase-Based Precise Point Positioning. UCGE Report No. 20170, Dept. of Geomatics Engineering, The University of Calgary, 143 pp.

13. Stewart, M.P., Houghton, H., and Ding, X.L., 1997. The STATFIX West Australia GPS Network, in Brunner, F. (ed.), Advances in Positioning and Reference Frames, Springer, Berlin, 155-160.

14. Tsakiri, M., 2008. GPS Processing Using Online Services, J. of Surveying Eng., 134(4): 115-125.

15. Wang, J., IZ, B. H. and Lu, C., 2002. Dependency of GPS Positioning Precision on Station Location. GPS Solutions, 6(1-2): 91-95.

16.Zumberge, J. F., Helflin, M.B., Jefferson, D.C., Watkins, M.M., and Webb, H., 1997. Precise Point Positioning for the Efficient and Robust Analysis of GPS Data from Large Networks. J. of Geophysical Research, 102(B3): 5005-5017. 